\title{
Intrinsic sphincter deficiency: what is it and does it matter anymore?
}

\author{
Steven Swift
}

Received: 12 August 2012 / Accepted: 14 August 2012 /Published online: 19 October 2012

(C) The International Urogynecological Association 2012

There was a time when intrinsic sphincter deficiency (ISD) had a definition that was clinically relevant and guided the therapeutic decision-making process. However, over time the definition has become muddied and has somewhat morphed into a vague term defined in various ways with various tests. Currently, I doubt that any two clinicians use the same definition, and ISD has become more of a euphemism than a defined disease. So how did we get here? It may be the result of some technology introduced in the mid 1990s that has been described by my colleague T. Fleming Mattox as "The single most important practice altering technology in urogynecology in our lifetime," the tensionfree vaginal tape (TVT).

The term ISD was originally coined by McGuire et al. in the urology literature from the 1980s and was used to describe a severe form of stress urinary incontinence, equating it to an earlier term "type III urinary incontinence" (reported in Blavais and Olsson [1]). In the urogynecology literature ISD was equated with a concept introduced by Sand et al. in 1987 in an article describing the "low pressure urethra" [2]. These terms were urodynamically defined as a Valsalva leak point pressure (VLPP) of less than $60 \mathrm{~mm}$ $\mathrm{H}_{2} \mathrm{O}$ and a maximal urethral closure pressure (MUCP) of less than $20 \mathrm{~cm} \mathrm{H}_{2} \mathrm{O}$ respectively. The disease ISD was a poor prognostic indicator and helped clinicians identify those patients at risk of failing our "gold standard" procedure for treating stress urinary incontinence, the Burch retropubic urethropexy. Subjects with ISD were felt to be better candidates for a pubovaginal sling. This literature contributed to ISD being formally defined in an Agency

\section{S. Swift $(\bowtie)$}

Department of Obstetrics and Gynecology,

Medical University of South Carolina,

Charleston, SC 29425, USA

e-mail: swifts@musc.edu for Healthcare Research and Quality (AHRQ) 1996 manual on the evaluation and treatment of urinary incontinence in adults as follows:

SUI may also be caused by an intrinsic urethral sphincter deficiency (ISD) ... In women, ISD is commonly associated with multiple incontinence surgical procedures, as well as with hypoestrogenism, aging, or both. In this condition, the urethral sphincter is unable to generate enough resistance to retain urine in the bladder, especially during stress maneuvers... Patients with ISD often leak continuously or with minimal exertion. In some patients, stress incontinence results from coexisting ISD and hypermobility of the urethra and bladder neck [3].

Then in the mid 1990s came literature on the tension-free vaginal tape demonstrating that ISD, as well as "typical" stress urinary incontinence with a hypermobile urethra, could both be effectively treated with a TVT. At this point, the definition of ISD began to become muddled. For a time ISD was defined as stress incontinence with a wellsupported bladder neck (lack of hypermobility) regardless of the VLPP or MUCP. As noted above, in the 1996 AHCPR document, a mention of lack of hypermobility being a component of ISD was noted. In the International Classification of Disease, 9th edition (ICD-9), ISD was defined as a disorder of the urethra "...due to intrinsic sphincter damage in which the urethra is usually well supported but there is posterior rotation and opening of the bladder neck and posterior urethra during straining" [4]. It was then felt that in subjects with ISD (without hypermobility) periurethral bulking agents were the treatment of choice, as these subjects did not do well with a Burch retropubic urethropexy. Here, again, the TVT dispelled this myth, as subjects with or without urethral hypermobility seem to do equally well with a TVT [5]. The final use of 
the definition of ISD came following the introduction of the transobturator tape tension-free sling (TOT). In subjects with ISD defined by a low-pressure urethra (MUCP $<20 \mathrm{~cm}$ $\mathrm{H}_{2} \mathrm{O}$ ), the TVT seemed more efficacious than the TOT, but recently that concept has been questioned $[6,7]$.

So now we are left with almost any form of stress urinary incontinence being treatable with either a TOT or TVT. Therefore, the reason for having the definition of ISD seems to be of historical significance only. Even the most recent International Urogynecologic Association (IUGA)/International Continence Society (ICS) joint report on the terminology for female pelvic floor dysfunction ignores the diagnosis of ISD and the most recent International Consultation on Incontinence has omitted the definition of ISD for no longer being useful [8].

Is this to say, then, that our surgical management of stress urinary incontinence has evolved to the point where all comers are effectively managed with either a TOT or TVT or perhaps a single incision sling? The answer to that question is inevitably "no." So what is the clinician left with in making surgical decisions about how patients with stress urinary incontinence are best managed? I don't think the answer to that question is currently available. I think that we need to have another look at how we view the urethral sphincter mechanism. I don't think we can dichotomize it into either a "normal" sphincter or one with an "intrinsic deficiency." Instead, we need to look at the urethral sphincter mechanism as a having a continuum of functional capabilities or deficiencies. In the recent TOMUS trial the investigators could not identify at what point subjects undergoing a TOT or TVT were at greatest risk of failure, but instead noted that as the ability of the urethral sphincter to generate a closing pressure, or force, declined, the risk of failure (with either a TVT or TOT) increased. In other work, the distensibility of the urethra to stretch and not its ability to generate a closure pressure is being evaluated as a measure of its functionality $[9,10]$. This work-while somewhat helpful in counseling patients about the risk of success or failure-will undoubtedly stimulate further research into alternative therapies. Currently, it cannot help us decide how best to treat our patients.

So, is the definition of ISD still helpful, or is it a relic of the past that should be discarded? That question may not yet be answerable, but we should not let old definitions continue to influence our research. Instead, we should view afresh the problem of surgical failure in our patients with stress urinary incontinence and how to best prevent it.

\section{References}

1. Blavais JG, Olsson CA (1988) Stress incontinence: definition and surgical approach. J Urol 139:727

2. Sand PK, Bowen LW, Panganiban R, Ostergard DR (1987) The low pressure urethra as a factor in failed retropubic urethropexy. Obstet Gynecol 69:399

3. Fantl JA et al (1996) Urinary incontinence in adults: acute and chronic management. Clinical practice guideline No. 2, 1996 update. Agency for Health Care Policy and Research, Rockville, AHCPR publication 96-0682

4. Ford B, Serling S (2009) Coders desk reference for diagnoses. Ingenix, Eden Prairie, MN

5. Rardin CR, Miklos J, Rosenblatt PL et al (2005) Outcomes of tension-free vaginal tape in women with intrinsic sphincter deficiency with or without urethral hypermobility. J Pelvic Med Surg 11:321

6. Schierlitz L, Dwyer PL, Rosamilia A et al (2012) Three-year followup of tension-free vaginal tape compared with transobturator tape in women with stress urinary incontinence and intrinsic sphincter deficiency: a randomized controlled trial. Obstet Gynecol 119:321-327

7. Nager C, Sirls L, Litman H, Richter H, Nygaard I, Chai T et al (2011) Baseline urodynamic predictors of treatment failure 1 year after mid urethral sling surgery. J Urol 186:597

8. Haylen BT, de Ridder D, Freeman RM, Swift SE, Berghmans B, Lee J, Monga A, Petri E, Rizk DE, Sand PK, Shaer GN (2010) An International Urogynecologic Association (IUGA)/International Continence Society (ICS) joint report on the terminology for female pelvic floor dysfunction. Int Urogynecol J 21:5

9. DeLancey JOL (2010) Why do women have stress urinary incontinence? Neurourol Urodyn 29:S13-S17

10. Klarskov N, Lose G (2007) Urethral pressure reflectometry: a novel technique for simultaneous recording of pressure and cross-sectional area in the female urethra. Neurourol Urodyn 26 (2):254-261 